Mehmet Akif Ersoy Üniversitesi Fen Bilimleri Enstitüsü Dergisi 9(1): 45-50 (2018)

The Journal of Graduate School of Natural and Applied Sciences of Mehmet Akif Ersoy University 9(1): $45-50$ (2018)

Araştırma Makalesi / Research Paper

\title{
Giresun-İkisu Doğu Ladini (Picea orientalis (L.) Link.) Gençleştirme Sahalarının Silvikültürel Değerlendirmesi
}

\author{
Hüseyin UÇARCl ${ }^{1}$, Nebi BíLíR ${ }^{2^{*}}$ \\ 1 Orman Bölge Müdürlüğü, Giresun \\ 2 Süleyman Demirel Üniversitesi, Orman Fakültesi, Isparta \\ Geliş Tarihi (Received): 31.12.2017, Kabul Tarihi (Accepted): 29.01.2018 \\ $\square$ Sorumlu Yazar (Corresponding author $\left.{ }^{*}\right):$ nebibilir@sdu.edu.tr \\ (C) +902462113837 且 +902462373948
}

ÖZ

Bu çalışma, önemli ticari ve sosyo-kültürel orman ağacı türlerimizden olan Doğu ladini (Picea Orientalis (L.) Link.)'nin Giresun-İkisi Orman İşletmesi örneğinde doğal gençleştirme çalışmalarının incelenmesi ve türün silvikültürel uygulamalarına katkı sağlanması amacıyla gerçekleştirilmiştir. Bu amaçla, türün 2011-2015 yılları arasında doğal gençleştirme uygulanmış dört farklı deneme sahasından ve her deneme alanından üç tekrarlı olarak 100 'er $\mathrm{m}^{2}$ (5x20m) büyüklüğünde alanlar örneklenmiştir. Örneklenen bu alanlarda çap, boy ve yaş ölçümleri ile birlikte gençleştirmenin başarı durumunun belirlenmesi amacıyla $2 \mathrm{~m}^{2}$ büyüklüğündeki alanlarda fidan sayımları gerçekleştirilmiştir. Uygulanan varyans analizi sonucunda Doğu ladini ile sahadaki diğer türlerin (Doğu Karadeniz göknarı ve Doğu kayını) gençliği arasında genel olarak boy, çap ve yaş için istatistiksel bakımdan anlamlı $(p \leq 0.05)$ farklılıklar bulunmuştur. Uygulanan korelasyon analizi sonucunda da, çalışmaya konu özellikler arasında istatistiksel bakımdan anlamlı ( $p \leq 0.05)$ pozitif ilişkiler belirlenmiştir. Yapılan sayımlar sonucunda deneme alanlarının gençleştirme çalışmaları bakımından başarıı (>\%85) olduğu sonucuna varıımıştır.

Anahtar Kelimeler: Doğu ladini, Gençleştirme, Silvikültür, Siper metodu

\section{Silvicultural Assessment of Regeneration Areas of Oriental Spruce (Picea orientalis (L.) Link.) in Giresun-İkisu Forest District}

\begin{abstract}
This study was carried out to examine natural regeneration of Oriental spruce (Picea orientalis (L.) Link.) which was an important commercial and social-cultural forest tree species to contribute silvicultural practices of the species in Giresun-Ikisu forest district. For the purpose, four natural regeneration area regenerated between 2011 and 2015 were sampled, and also three replicates $100 \mathrm{~m}^{2}(5 \times 20 \mathrm{~m})$ from each area. Height, diameter and age of seedlings were measured in each replicates. Beside, seedlings were counted by $2 \mathrm{~m}^{2}$ square to estimate regeneration success. Significant differences $(p \leq 0.05)$ were found among seedlings of Picea orientalis, Abies nordmanniana and Fagus orientalis for diameter, height, and age according to results of analysis of variance. There were significant phenotypic correlations $(p \leq 0.05, r>0.54)$ among the characters based on results of correlation. Natural regeneration was successful (> $85 \%$ ) based on number of counted seedlings.
\end{abstract}

Keywords: Oriental spruce, Regeneration, Silviculture, Shelterwood method 


\section{Giriş}

Doğu ladini (Picea Orientalis (L.) Link), sivri tepe, dolgun ve düzgün gövdeler yapan, 40-50 metre bazen 60 metre kadar boylanabilen 1.5-2 metre çap yapabilen piramidal görünüşlü, sık dallı (serbest büyüyenler dibe kadar dallı), birinci sınıf orman ağaçlarımızdandır (Anşin, 1988). Asli ağaç türlerinin en önemlileri arasında yer alan Doğu ladini, Ülkemiz ormanları içinde kapladığı 472182 ha yayılışıyla, toplam orman alanının \%2.3'nü oluşturmaktadır (Konukçu, 2001). Bu tür, Kuzey Doğu Anadolu'nun sahil kesimleri ve Kafkasya'da 400 23'-430 50' enlemleri ile 370 40'-440 13' boylamları arasında doğal olarak yayılmaktadır (Anonim, 1989). Ülkemizde yayılışının doğu sınırı Türk-Rus sınırından başlar ve batıda Ordu ili yakınlarında Melet ırmağı ile son bulur (Anşin ve Özkan, 2001). Ordu-Melet ırmağının doğusundaki bu yayılışı, Giresun, Gümüşhane, Trabzon, Rize ve Artvin mıntıkalarında 1000-2050 metre yükseltiler arasında olup buradan Gürcistan/Rusya'ya geçer (Saatçioğlu, 1969). Gölgeye dayanma yeteneği bakımından Doğu ladininin yarı gölge ağaçları sınıfında olduğu kabul edilmektedir. Ancak bu ağaç türünün gölgeye dayanma yeteneğinin yüksek olduğu ve az ışıkta da uzun süre yaşayabildiği saptanmış olduğundan, ışık isteği bakımından daha ziyade gölge ağacı olarak kabul edilmelidir (Demirci, 1991). Nispi nemi yüksek, sisli ve su açığı olmayan nemli bölgelerde yayılış göstermekte özellikle güney yamaçlardan kaçınmakta, kuzey yamaçlarda sarıçam, yer yerde göknar'la karışıma girmektedir. Doğu ladini için yağmurdan ziyade toprağın ve havanın nemi daha önemlidir (Saatçioğlu, 1971).

Mevcut orman alanlarımızdaki verimsiz orman alanı oranı (\%47), Doğu ladini ormanlarında da kendini göstermekte ve bu Doğu ladini ormanlarının \%31'i verimsiz yani kendinden beklenen faydayı sağlayamamaktadır (Anonim, 2015). Oysa türün odunu, sanayide geniş ölçüde kullanım alanı bulurken, ayrıca ormanları bölge halkı için sosyal ve ekonomik yönden de büyük önem taşımaktadır (Akalp, 1978). Türün gerek ekonomik ve gerekse sosyo-kültürel önemi türün mevcut ormanlarının korunması ile verimsiz ormanlarının verimli ormanlara dönüştürülmesinin ve dolayısıyla tür üzerinde yapılacak ağaçlandırma, gençleştirme gibi silvikültürel uygulamaların önem ve ivediliğini de artırmaktadır. Bu bağlamda çalışmada; Giresun-İkisu Orman İşletme Şefliği Doğu ladini sahalarında yapılan gençleştirme çalışmalarındaki silvikültürel başarı ve/veya başarısızlık nedenlerinin belirlenmesi; silvikültürel değerlendirmelerde bulunulması, türün gençleştirme çalışmalarında karşılaşılan sorunlara çözüm önerilerinde bulunulması amaçlanmıştır.

\section{MATERYAL VE YÖNTEM}

Çalışmada araştırma alanı olarak; Giresun Orman Bölge Müdürlüğü, Dereli Orman İşletme Müdürlügü̈ne bağlı İkisu Orman İşletme Şefliği sınırları içerisindeki 2011-2015 yıllarında gerçekleştirilmiş doğal gençleştirme sahalarındaki 39 (B39), 53 (B53), 55 (B55) ve 62 (B62) nolu bölmeler örneklenmiştir (Tablo 1).

Bu örnek alanlar, Dereli Orman İşletmesi sınırları içinde kalan Doğu ladini gençleştirme sahalarına ait son 5 yıllık 2011-2015 Amenajman ve Silvikültür Plan verileri ışığında hazırlanan veri tabanına göre mevcut gençleştirme sahalarında rastgele belirlenmiştir. Örneklenen alanlarda, fidan özelliklerinin ölçümü için her bölmeden $100 \mathrm{~m}^{2}(5 \times 20 \mathrm{~m})$ büyüklüğünde üçer tekrar yapılmıştır. Gençleştirmenin başarı durumunun belirlenmesi için ise fidan sayımlarında $2 \mathrm{~m}^{2}(140 \times 145 \mathrm{~cm})^{\prime}$ 'lik fidan sayım çerçevesi kullanılmıştır.

Belirlenen örnek alanlarda;

Gençliklerin yaş, çap ve boyu ile $\mathrm{m}^{2}$ deki fidan sayısı, diri örtü durumu, yan meşçereye olan mesafe, boşaltma kesimi öncesi hektardaki ağaç sayısı ile kapalıık oranları ölçülmüştür.

Elde edilen veriler SPSS istatistik paket programında değerlendirilerek, özelliklere ilişkin ortalama değerler belirlenmiştir. Deneme alanları içinde türlere ait gençliklerin, çalışmaya konu özellikler bakımından karşılaştırılmasında aşağıdaki basit (ANOVA) varyans analizi modeli kullanılmıştır.

$$
Y_{i j k}=\mu+F_{i}+B(F)_{j(i)}+e_{i j k}
$$

Burada $Y_{i j k}$ i. Örnek alandaki j. türün k. gençliğinin değerini; $\mu$ genel ortalamayı; $\mathrm{B}(\mathrm{F})_{j(i)}$ i. tekrardaki j. türün etkisini; $e_{i j k}$ ise hatayı göstermektedir.

Çalışmaya konu özellikler arasındaki ilişkiler ise korelasyon analizi ile belirlenmiştir.

\section{BULGULAR VE TARTIŞMA}

Lcd1/a meşcere tipindeki B39 nolu bölmede 2011 yılında doğal gençleştirme uygulanmış ve sahada boşaltma kesimi öncesi yaşları 20-38 arasında değişen 11 Doğu ladini ile 82 ve 55 yaşında iki adet Doğu Karadeniz göknarı bulunmaktadır. Sahada $100 \mathrm{~m}^{2}$ lik $\left(=3 \times 100 \mathrm{~m}^{2}\right)$ üç tekrardaki 61 Doğu ladini ve 28 Doğu Karadeniz göknarı (Abies nordmanniana (Steven) S) gençliğinin yaş, çap ve boyuna ilişkin ortalama değerler Tablo 2'de verilmiştir. 
Tablo 1. Deneme alanlarına ilişkin genel bilgiler

\begin{tabular}{cccccc}
\hline $\begin{array}{c}\text { Bölme } \\
\text { No }\end{array}$ & Kodu & $\begin{array}{c}\text { Aktüel } \\
\text { Meşcere } \\
\text { Tipi }\end{array}$ & $\begin{array}{c}\text { Coğrafi Ko- } \\
\text { ordinatları } \\
\text { (WGS84) }\end{array}$ & Bakı & $\begin{array}{c}\text { Yükseklik } \\
\text { (m) }\end{array}$ \\
\hline 39 & B39 & Lcd1/a & $\begin{array}{c}450180- \\
4493945\end{array}$ & Batı & 1750 \\
53 & B53 & LKncd2 & $\begin{array}{c}447565- \\
4492860\end{array}$ & Güney & 1700 \\
55 & B55 & LGcd2 & $\begin{array}{c}447982- \\
4493330\end{array}$ & Kuzey & 1650 \\
62 & B62 & La & $\begin{array}{c}450540- \\
4492620\end{array}$ & Kuzey & 1700 \\
\hline
\end{tabular}

Tablo 2. B39 nolu bölmedeki gençliklerde sayı, çap, boy ve yaş değerleri

\begin{tabular}{ccccc}
\hline Tür & Birey sayısı & Çap $(\mathbf{m m})$ & Boy $(\mathbf{c m})$ & Yaş $(\mathbf{c m})$ \\
\hline & \multicolumn{5}{c}{ Ortalama } \\
\hline Doğu Ladini & 61 & 22.3 & 84.9 & 8 \\
D.K. Göknar & 28 & 16.7 & 71.7 & 6 \\
& & Minimum-Maksimum & \\
\hline Doğu Ladini & - & $2.2-116.5$ & $2.10-640$ & $2-10$ \\
D.K. Göknar & - & $0.9-64.0$ & $2.2-317$ & $1-12$ \\
\hline
\end{tabular}

Tablo 2'den de görüldüğü üzere Doğu ladini gençlikleri Doğu Karadeniz göknarı gençliklerine oranla daha fazla gelişim göstermiştir. Bu gelişim performansında iki tür arasındaki yaş farklıığının da etkili olduğu söylenebilir. 8 yaşlı Doğu ladini gençliğinde boy $84.9 \mathrm{~cm}$ ve çap 22.3 mm; 6 yaşlı Doğu Karadeniz göknarı gençliklerinde ise bu değerler sırasıyla $71.7 \mathrm{~cm}$ ve $16.7 \mathrm{~mm}$ 'dir (Tablo 2). Ancak boya ilişkin yıllık gelişim değerlerine bakıldığında, Doğu ladini gençliklerinin yıllık ortalama boy gelişiminin $10.6 \mathrm{~cm}$, Doğu Karadeniz göknarı gençliklerinin ise yıllık ortalama $12 \mathrm{~cm}$ boy gelişimi yaptığı görülmektedir. Doğu ladini gençliğinin $70-80 \mathrm{~cm}$ boya, bonitetlere göre 12-16 yaşında ulaşabildiğini belirtmektedir (Eyüboğlu, 1989). Dolayısıyla tarafımızca elde edilen boy değerleri, tür üzerinde gerçekleştirilen önceki çalışmada (Eyüboğlu, 1989) belirtilen boy değerlerine göre daha yüksektir. Ancak bu gelişimde gençliğin yaşı, uygulanan gençleştirme yöntemim ile birlikte birçok genetiksel (tohum ağaçlarının genotipi vb.) ve çevresel faktörler (sahanın bakısı, yükseltisi, diri örtü durumu vb.) rol oynayabilmektedir. Uygulanan varyans analizi sonucunda, yaş bakımından türlerin gençliği arasında istatistiksel bakımdan anlamlı farklılıklar bulunurken boy ve çap bakımından anlamlı farklılıklar bulunamamıştır. Dolayısıyla, Doğu ladini karışık meşcerelerinde $(L+G, L+K n, L+C ̧ s)$ yapılan doğal gençleştirme çalışmalarından sağlıklı sonuç alınabilmesi için, karışımı oluşturan ağaç türlerinin ışık, sıcaklık, toprak istekleri, sipere dayanma durumu, tohum yılları, tohum yıllarının tekrarı, tohum döküm zamanı gençliğin siper intiyacı ve biyolojik bağımsızlığa kavuşma yaşı ile karşıııkı büyüme ilişkileri vb. özelliklerinin bilinmesi gerekir (Memiş, 2014). Uygulanan korelasyon analizi sonucunda da her iki türün gençliğinin yaş, çap ve boyu arasında istatistiksel bakımdan anlamlı ilişkiler belirlenmiştir. Bu sonuç ileride uygulanabilecek muhtemel silvikültürel müdahaleler için önem taşımaktadır.

Güney bakıda yer alan LKncd2 meşcere tipindeki B53 nolu bölmede, 50 Doğu ladini ve 39 Doğu kayını gençliğinin yaş, çap ve boyuna ilişkin ortalama değerler ışığında Doğu kayını gençlikleri Doğu ladini gençliklerine oranla daha fazla gelişim gösterdiği ortaya çıkmıştır (Tablo 3). 
Tablo 3. B53 nolu bölmedeki gençliklerde sayı, çap, boy ve yaş değerleri

\begin{tabular}{ccccc}
\hline Tür & $\begin{array}{c}\text { Birey } \\
\text { sayısı }\end{array}$ & $\begin{array}{c}\text { Çap } \\
(\mathbf{m m})\end{array}$ & $\begin{array}{c}\text { Boy }( \\
\mathbf{c m})\end{array}$ & $\begin{array}{c}\text { Yaş } \\
\text { (cm) }\end{array}$ \\
\hline \multicolumn{5}{c}{ Ortalama } \\
\hline $\begin{array}{c}\text { Doğu } \\
\text { Ladini } \\
\text { Doğu } \\
\text { Kayını }\end{array}$ & 50 & 9.2 & 22.6 & 4 \\
& 39 & $\begin{array}{c}12.6 \\
\text { Minimum-Maksimum }\end{array}$ & 43.6 & 3 \\
\hline $\begin{array}{c}\text { Doğu } \\
\text { Ladini } \\
\text { Doğu } \\
\text { Kayını }\end{array}$ & - & $1.8-20.9$ & $\begin{array}{c}2.2-5.3 \\
12.0-\end{array}$ & $1-9$ \\
\hline
\end{tabular}

Uygulanan varyans analizi sonucunda da yaş, çap ve boyu bakımından Doğu kayını ve Doğu ladini gençlikleri arasında istatistiksel bakımdan anlamlı $(p \leq 0.05)$ farklılıklar belirlenmiştir. Bununla birlikte uygulanan korelasyon analizi sonucunda, sahada gençliği mevcut her iki türde de yaş, çap ile boy arasında ileride yapılacak muhtemel silvikültürel müdahaleler için önem taşıyan, anlamlı $(p \leq 0.05, r>0.68)$ ilişkiler belirlenmiştir.

Kuzey bakı ve 1650 metre yükseltiye sahip LGcd2 meşcere tipindeki B55 nolu bölmede, 2009 yılında doğal gençleştirme çalışması uygulanmış, sahadaki 66 Doğu ladini ve 22 Doğu Karadeniz göknarı gençliği üzerinde yaş, çap ve boy ölçümleri gerçekleştirilmiştir. Elde edilen sonuçlar ışığında (Tablo 4) Doğu Karadeniz göknarı ve Doğu ladini gençlikleri benzer gelişim performansı gösterdiği ortaya çıkmıştır. Zira 7 yaşlı Doğu ladini gençliğinde boy $36.7 \mathrm{~cm}$ ve çap $9.1 \mathrm{~mm} ; 8$ yaşlı Doğu kayını gençliklerinde ise bu değerler sırasıyla
$31.2 \mathrm{~cm}$ ve $8.9 \mathrm{~mm}$ bulunmuştur (Tablo 4). Gölhisar Orman İşletmesi, Tefenni Şefliğinde yapılan çalışmada; 1 yaşında ve 1 yıl siperde kalmış karaçam gençliklerinin, 3 yaşına kadar siperde kalmış olanlara göre daha fazla boy büyümesi yaptığını tespit etmişlerdir [Eler ve ark., 1989). Dolayısıyla bu gelişim farklılığında birçok faktör rol oynayabilir.

B55 nolu bölmedeki Doğu Karadeniz göknarı ve Doğu ladini gençliklerinin gelişim performansı benzerlikleri uygulanan varyans analizi sonuçları ile de desteklenmiş olup, boy, çap ve yaş bakımından türlerin gençliği arasında istatistiksel bakımdan anlamlı $(p \leq 0.05)$ farklılıklar bulunamamıştır. Korelasyon analizi sonucunda, her iki türde de yaş, çap ile boy arasında istatistiksel bakımdan anlamlı $(p \leq 0.05, r>0.68)$ pozitif ilişkiler belirlenmiştir.

Tablo 4. B55 nolu bölmedeki gençliklerde sayı, çap, boy ve yaş değerleri

\begin{tabular}{ccccc}
\hline Tür & Birey sayısı & Çap $(\mathbf{m m})$ & Boy $(\mathbf{c m})$ & Yaş $(\mathbf{c m})$ \\
\hline Doğu Ladini & \multicolumn{5}{c}{ Ortalama } \\
Doğu Kayını & 66 & 9.1 & 36.7 & 7 \\
& 22 & $\begin{array}{c}8.9 \\
\text { Minimum-Maksimum }\end{array}$ & 31.2 & 8 \\
\hline Doğu Ladini & - & $1.6-5.3$ & $7.0-196.0$ & $2-7$ \\
Doğu Kayını & - & $2.6-19.2$ & $7.0-82.0$ & $2-6$ \\
\hline
\end{tabular}

Kuzey bakı ve 1700 metre yükseltiye sahip La meşcere tipindeki B62 nolu bölmede 2010 yilında doğal gençleştirme çalışması uygulanmış 9 yaşındaki 89 Doğu ladini gençliğinde ortalama çap $30.2 \mathrm{~mm}$ ve boy $103.9 \mathrm{~cm}$ belirlenmiştir (Tablo 5 ). Bunlara ek olarak bu deneme alanındaki gençliklerin yaş, çap ve boy değerleri arasında geniş farklıııklar bulunmuştur. Gerçekleştirilen bir çalışmada, Doğu ladini gençliklerinin 2 ve 2'nin katı yaşlarda olmak üzere 20 yaşına kadar ulaştığı boylar sırasıyla $5.9 \mathrm{~cm}, 14.6 \mathrm{~cm}, 26.0 \mathrm{~cm}, 35.3 \mathrm{~cm}, 49.8 \mathrm{~cm}$, $66.3 \mathrm{~cm}, 89.1 \mathrm{~cm}, 115.4 \mathrm{~cm}, 146.0 \mathrm{~cm}$ ve $190.5 \mathrm{~cm}$ olduğu ve gençliğinin 7-10 yılda $60-70 \mathrm{~cm}$ boya ulaştığını; gençlikteki yavaş büyüme 10-15 yaşından sonra bonitet değerlerine göre hızlandığı belirlenmiştir (Demirci, 1991). Tarafımızca elde edilen boy değerleri bu çalışmaya (Demirci, 1991) göre düşük kalmıştır. Gerçekleştirilen bir çalışmada, gençleştirme çalışmaları küçük alanlarda yapılacaksa kesim yönünün belirlenmesi için mutlaka kesim anahtarına dikkat edilmesi; kesim anahtarında, hakim rüzgar yönü, transport ve bakı unsurları dikkate alınması gerektiğini belirtmektedir (Demirci, 2005). 
Tablo 5. B62 nolu bölmedeki gençliklerde sayı, çap, boy ve yaş değerleri

\begin{tabular}{ccccc}
\hline Tür & Birey sayısı & Çap (mm) & Boy $(\mathbf{c m})$ & Yaş $(\mathbf{c m})$ \\
\hline Doğu Ladini & \multicolumn{4}{c}{ Ortalama } \\
& 89 & $\begin{array}{c}30.2 \\
\text { Minimum-Maksimum }\end{array}$ & 103.9 \\
\hline Doğu Ladini & - & $2-75.5$ & $7-291$ & $3-15$ \\
\hline
\end{tabular}

Gençliklerin çalışmaya konu büyüme özellikleri arasındaki ilişkileri belirlemek amacıyla uygulanan korelasyon analizi sonucunda, gençliklerin yaşı, çapı ile boyu arasında anlamlı $(p \leq 0.05, r>0.73)$ pozitif ilişkiler belirlenmiştir.

Yapılan sayımlar sonucunda B39 nolu deneme alanının $\% 93$; B53 nolu sahanın \%98; B55 nolu deneme alanın $\% 85$ ve $\mathrm{B} 62$ nolu sahanın ise $\% 90$ oranında gençleştirme çalışmaları bakımından başarılı olduğu sonucuna varılmıştır. Orman Genel Müdürlüğü gençleştirme başarısını "Fidan Sayım Esasları ve Tutanağı" çerçevesinde yapılan fidan sayımlarıyla belirlemekte; saf ve karışık meşcereler için düzenlenen sayım sonuçları ağaç türlerine göre ayrı ayrı değerlendirilip başarı derecesi, \% 80 için iyi, \% 60-79 için orta ve \% 40-59 arasında ise zayıf ifadeleri kullanılmaktadır (Anonim, 1991). Ancak meşcerenin ileri aşaması da göz önüne alınarak sahaya gelen gençlik sayısıyla birlikte, gençliğin alana dağılımı da başarıda rol oynayan önemli etmenler olarak göz önüne alınabilir, ancak bu dağılım yapılacak gençlik bakımları veya hazırlık kesimleri ile de dengelenebilir. Biyolojik olarak bağımsız hale gelmiş boylu doğal karaçam gençliklerinde kabul edilebilir bir gençlik için $\mathrm{m}^{2}$ de ortalama 2-3, sıklıklarında 1-2 adet iyi kalitede fert bulunmalıdır. Gençleştirme çalışmalarında başarı için hektarda 30-50 bin fidan bulunması gerekir (Saatçioğlu, 1979). Çam türlerinde büyük alan siper gençleştirme metodunu başarılı saymak için, uygulama sonucu hektarda 30000 ila 35000 adet fidanın homojen bir dağılımda bulunması gerektiğini belirtmektedir (Atay, 1990). Bir başka çalışmada ise amaçsız müdahaleler sonucu oluşmuş gençliklerin yeterli olması için, $\mathrm{m}^{2}$ de 1-2 fidanın yeterli olduğu belirtilmektedir (Ata, 1995).

Örneklenen B39 nolu bölmede Doğu ladini gençliğinin yaklaşık 10 yaşlarında biyolojik bağımsızığına ulaştığı ve bunun bireysel olarak 3-11 yıl arasında değiştiği; bu yaşın Doğu Karadeniz göknarında 4-5 yıl olduğu ve bireysel olarak 8 yaşına çıktığı; B55 nolu bölmede ise Doğu ladini gençliğinin 5 yaşlarında; örneklenen B62 nolu bölmede ise Doğu ladini gençliğinin 3-8 yaşlarında biyolojik bağımsızlığına ulaştığı ortaya çıkmıştır. Doğu ladininin yayılış alanlarındaki diri örtünün yıllık ortalama boyu 1m'ye ulaşmaktadır. Doğu Ladini ilk yıllarda yavaş büyüdüğünden fidanların diri örtünün üzerine çıkması uzun zaman almaktadır. Bu boya ulaşamayan fidanlar (80 cm den az), diri örtüden zarar görmekte, dolayısıyla da biyolojik bağımsızlığına tam anlamıyla kavuşamamaktadırlar (Eyüboğlu, 1989). Doğu ladini'nde eğer tohumlama kesiminden sonra gelen gençlik sayı ve dağılımı yeterli değilse 2. ve 3. bol tohum yılından da yararlanılabileceği belirtilmektedir (Anonim, 1989). Çaıışmamızda değerlendirilen gençliklerdeki yaş farklııkları ve biyolojik bağımsızlığına ulaşım yaşı farklııkları sahadaki öncü gençlikler ile türde birden fazla bol tohum yılından yararlanma gibi silvikültürel uygulamalar için önem taşımaktadır.

\section{TEŞEKKÜR}

Bu çalışma, Prof. Dr. Nebi Bilir danışmanlığında tamamlanan yüksek lisans tez çalışmasının bir bölümünü içermektedir. Tez çalışmasındaki değerli eleştiri ve katkılarından dolayı sınav jüri üyeleri ile ölçümler sırasında yardımları nedeniyle Giresun Orman Bölge Müdürlüğü çalışanlarına teşekkür ederiz.

\section{KAYNAKLAR}

Akalp, T. (1978). Türkiye'deki Doğu ladini (Picea orieantalis Lk. Carr) ormanlarında hasılat araştırmaları. İstanbul Üniversitesi, Fen Bilimleri Enstitüsü, Doktora Tezi, 145 s, İstanbul.

Anonim (1989). Doğu Ladin El Kitabı. Ormancılık Araştırma Enstitüsü Yayınları. Ankara, 288s.

Anonim (1991). T.C. Tarım, Orman ve Köyişleri Bakanlığı, Orman Genel Müdürlüğü, Ağaçlandırma ve Silvikültür Dairesi Başkanlığı, 22.07.1991 tarih ve 3291-Ek:1 sayılı Gençleştirme Uygulamaları hakkında tamim. T.C. Tarım, Orman ve Köyişleri Bakanlığı, Orman Genel Müdürlüğü, Ağaçlandırma ve Silvikültür Dairesi Başkanlığı, Ankara.

Anonim (2015). Orman varlığımız. Türkiye Cumhuriyeti Çevre ve Orman Bakanlığı Orman Genel Müdürlüğü, Ankara, 28 $\mathrm{s.}$

Anşin, R. (1988). Tohumlu bitkiler I. Cilt Gymnospermae (Açık Tohumlular). Karadeniz Teknik Üniversitesi Orman Fakültesi Yayınları. Trabzon, 262s.

Anşin, R., Özkan, C. Z. (2001). Tohumlu Bitkiler (Spermatophyta) Odunsu Taksonlar. Karadeniz Teknik Üniversitesi Orman Fakültesi Yayınları. Trabzon, 450s.

Ata, C. (1995). Silvikültür Tekniği. Zonguldak Karaelmas Üniversitesi Bartın Orman Fakültesi Yayınları. Bartın, 453s.

Atay, İ. (1990). Silvikültür-II. İstanbul Üniversitesi Orman Fakültesi Yayınlar. İstanbul, 242s. 
Demirci, A. (1991). Doğu Ladini (Picea orientalis (L.) Link.) Doğu Kayını (Fagus orientalis Lipsky.) karışık meşcerelerinin gençleştirilmesi. Karadeniz Teknik Üniversitesi, Fen Bilimleri Enstitüsü, Doktora Tezi, 223 s, Trabzon.

Demirci, A. (2005). Silvikültür Tekniği Ders Notu. Karadeniz Teknik Üniversitesi Orman Fakültesi Yayınları. Trabzon, 80 s.

Eler, Ü., Genek, A., Yıldırım, K. (1989). Karaçam (Pinus nigra Arnold.) Gençliklerinde Erken Boşaltma ve Seyreltmenin Fidan Büyümesi Üzerine Etkileri. Ormancılık Araştırma Enstitüsü Yayınları. Ankara, 14s.

Eyüboğlu, A. (1989). Doğu Ladininin Doğal Gençleştirilmesi. Ormancılık Araştırma Enstitü Yayınları. Ankara, 58s.
Konukçu, M. (2001). Ormanlar ve Ormancılığımız. Devlet Planlama Teşkilatı Yayınları. Ankara, 123s.

Memiş, O. (2014). Amenajman planlarında gençleştirme sahaların değerlendirilmesi (Hamsiköy Şefliği örneği). Karadeniz Teknik Üniversitesi, Fen Bilimleri Enstitüsü, Yüksek Lisans Tezi, $62 \mathrm{~s}$, Trabzon.

Saatçioğlu, F. (1969). Silvikültür I, Silvikültürün Biyolojik Esasları ve Prensipleri. İstanbul Üniversitesi Orman Fakültesi Yayınlar. İstanbul, 323s.

Saatçioğlu, F. (1971). Orman Bakımı. İstanbul Üniversitesi Orman Fakültesi Yayınları. İstanbul, $303 \mathrm{~s}$.

Saatçioğlu, F. (1979). Silvikültür II (Silvikültürün Tekniği). İstanbul Üniversitesi Orman Fakültesi Yayınları. İstanbul, $562 s$. 